\title{
AN INTEGRATED IGEC-CSS DESIGN COURSE FOR GRADUATE STUDENTS IN PETROLEUM ENGINEERING
}

\author{
Gioia Falcone \\ Behnam J afarpour \\ Maria Barrufet
}

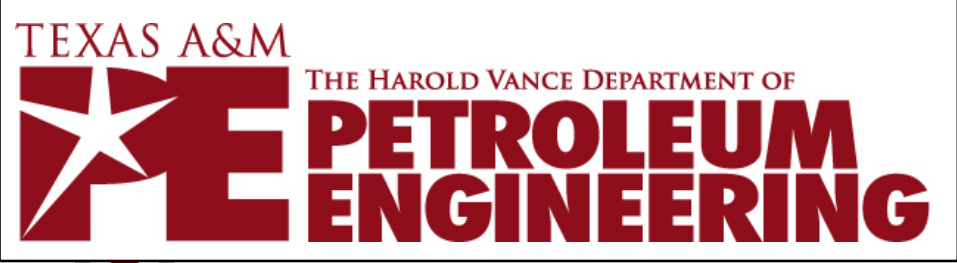

Virtual Conference on Climate Change and CO2 Storage, 3rd December 2008 


\section{Summary}

- Introduction to the course

- The design project

- FutureGen field case

- Workflow

- Lessons learnt \& conclusions 


\section{Introdurtion to the Gourse}

- A new graduate course on $\mathrm{CO}_{2}$ Capture and Uses was offered for the first time at Texas $A \& M$, Pet. Eng., in Fall 2008.

- A multidisciplinary team of instructors from the Pet. Eng. \& Chem. Eng. departments was assembled to ensure the appropriate expertise.

- The objective of the course is to let the students understand the need for / potential of Carbon Capture and Storage (CCS) \& Enhanced Oil Recovery (EOR). 


\section{Course contents \& multidiseiplinary team}

\section{Topic}

- Course Overview and Purpose

- Geological Screening and Site Characterization

- Separation Aspect and Cost-Efficiency Analysis

- Boosting, Transportation, and Injection

- I njectivity and Well Design

- Use of CO2 for EOR

- Modeling Tools and Techniques, Leakage Pathways-

- Economic and Regulatory Aspects

\section{Instructor (Prof.)}

Robert Lane,

Maria Barrufet

Walter Ayers

Carl Laird

Gioia Falcone

Hisham Nasr-El-Din

David Schechter

Behnam Jafarpour

Christine Economides 


\section{The design project}

The course includes a term project - the students design a CCS system based on data available from the FutureGen project (www. futuregenalliance.org/).

The following steps are included in the design project:

1.Site characterisation

2. $\mathrm{CO}_{2}$ capture \& separation

3. $\mathrm{CO}_{2}$ boosting, transport and injection

4. Mass balance \& numerical flow simulation

5. Risk, monitoring, regulations \& economic evaluation 


\section{Site characterisation - Brazos, Texas}

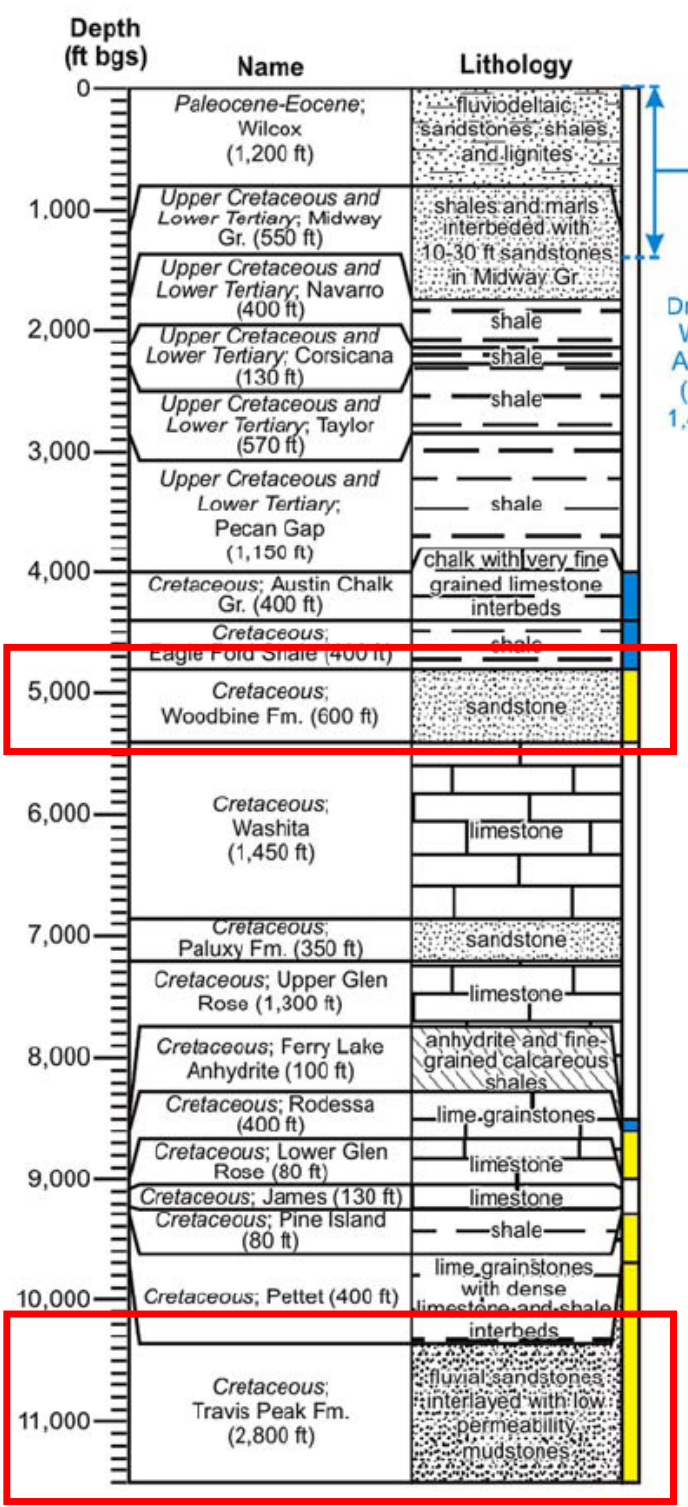

\begin{tabular}{||c|c|c||}
\hline Parameter & $\begin{array}{c}\text { Brazos } \\
\text { Woodbine }\end{array}$ & $\begin{array}{c}\text { Brazos } \\
\text { Travis Peak }\end{array}$ \\
\hline \hline Depth to top of injection horizon (ft) & 4800 & 9200 \\
\hline No. of wells & 2 & 1 \\
\hline Flow split/well & $45 \%$ & $10 \%$ \\
\hline Flow rate/well (lb/hr) & 283,130 & 62,917 \\
\hline Max. injection pressure (psi) & 3197 & 6114 \\
\hline Required injection pressure (psi) & 2496 & 6114 \\
\hline
\end{tabular}

The Woodbine formation is a 500 -foot thick clean sandstone. For Lower Woodbine sandstones, porosity of $25 \%$, with permeability of several hundreds md to $1,200 \mathrm{md}$. For Upper Woodbine sandstones, porosity of $25-30 \%$, with permeability $>3,000 \mathrm{md}$.

The Travis Peak formation, the optional secondary target sequestration formation, consists of 0.5 mile of stacked fluvial sandstones interbedded with lowpermeability mudstones, comprising 800 to 900 feet of net sandstone, with porosity of $5-8 \%$. 


\title{
CO2 capture and separation
}

- Post-combustion fuel gas

Co conversion separation

- Physical and chemical absorption

- Capture efficiency

- Tools used by students: ASPEN, ProMax

\author{
cal
}

Heat recovery

|

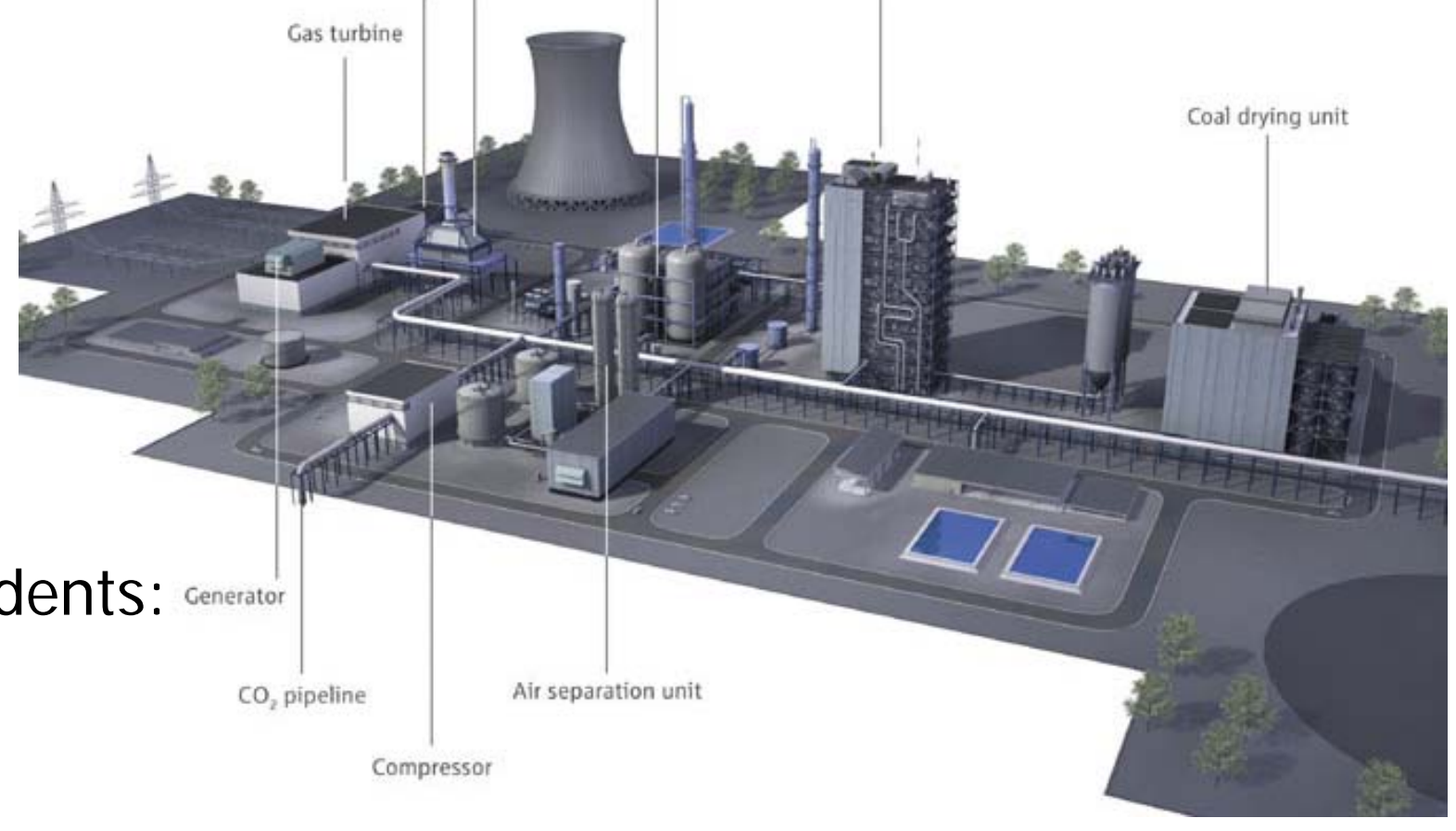




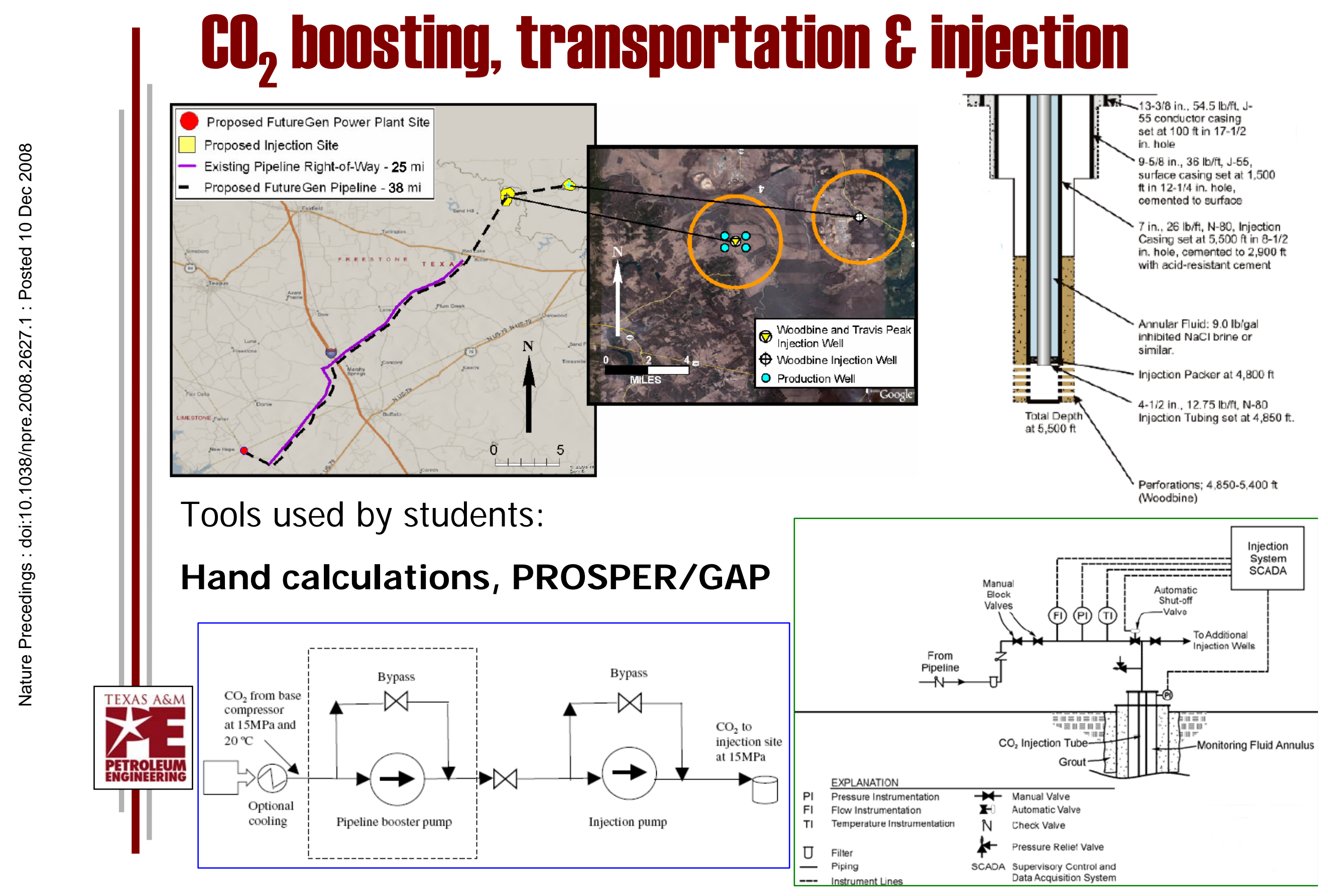




\section{Conclusions}

- With this new course, engineering students are offered a unique opportunity to learn about integrated IGCC-CCS systems.

- Conventional Pet. Eng. \& Chem. Eng. skills and techniques fully complement an integrated approach to the contemporary energy scenario.

- A design project based on a real field case is ideal for scholarly purposes - we plan on using more field data as they become available. 


\title{
AN INTEGRATED IGEC-CSS DESIGN COURSE FOR GRADUATE STUDENTS IN PETROLEUM ENGINEERING
}

\author{
Gioia Falcone \\ Behnam J afarpour \\ Maria Barrufet
}

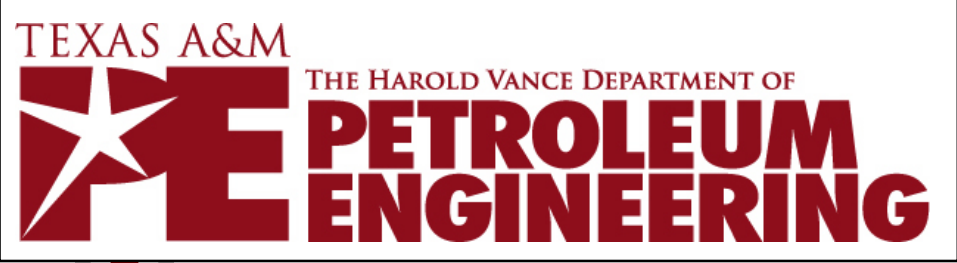

Virtual Conference on Climate Change and CO2 Storage, 3rd December 2008 